\title{
PROBLEMAS Y VICISITUDES DE LA POLITICA COYUNTURAL
}

La crisis económica que empezó en 1929 y tuvo por corolario varios años de desocupación masiva en el mundo entero, es probablemente el acontecimiento de mayor importancia y de más graves consecuencias en la historia económica de la primera mitad del siglo XX. Desde entonces, no hay gobierno ni partido político que no se vea en la obligación de hacer figurar la plena ocupación y la seguridad social entre los puntos más importantes de sus programas, ni que en su política económica práctica, pueda dejar de tomar todas las providencias imaginables para impedir las fluctuaciones coyunturales y asegurar un crecimiento constante de la economía.

Al terminar la segunda guerra mundial, muchos economistas, tanto teóricos como prácticos, pensaban que el paso de la economía de guerra a la economía de paz provecaría la aparición de fenómenos de crisis similares a los que se manifestaron después de la primera guerra mundial. Otros economistas, principalmente los continuadores de Keynes, consideraban que el estado moderno está en condiciones de suavizar en gran medida las fluctuaciones coyunturales y asegurar un nivel de ocupación constantemente alto, mediante la aplicación sistemática de medidas de política económica, especialmente de carácter fiscal. 
Considerando la evolución de la coyuntura desde el fin de la guerra, notamos que:

1) El paso de la economía de guerra a la economía de paz ha ocasionado, en los Estados Unidos y en Europa, menos dificultades de lo que se temía.

2) La reconstrucción de la economía en los países europeos que han sufrido directamente la guerra, se ha realizado, desde 1948 aproximadamente, con unc rapidez extraordinaria, y el au. mento de la producción, en los países industriales occidentales más importantes, ha dejado ctrás el ritmo de preguerra.

3) En los años transcurridos desde el fin de la guerra, el desarrollo económico del mundo occidental no ha sido interrumpido por ninguna crisis general que fuera caracterizada por la desocupación masiva y la contracción del producto social o del ingreso nacional.

Los Estados Unidos han sufrido, desde el fin de la guerra, tres recesos (1949, 1953/54 y 1957/58), que fueron superados bastante rápidamente, y que tuvieron más el carácter de perturb- $x$ ciones parciales que de depresiones económicas generales. Mientras tanto, la expansión económica europea se desarrolló con un ritmo más regular, y los recesos de los Estados Unidos la alcanzaron solamente en forma atenuada. En conjunto, se puede decir que las fluctuaciones cíclicas en la postguerra han sido mucho más suaves que entre las dos guerras mundiales. Pero esta situación no nos permite inferir que estaremos siempre invulnerables a las crisis.

La comprensión de la problemática actual de la política coyuntural, exige el conocimiento de los cambios por los cuales han pasado las fluctuaciones coyunturales a través de su historia, y de sus consecuencias para la política anticíclica. Pero, antes de abordar el estudio de estos problemas, conviene indicar en pocas palabras lo que entendemos por "coyuntura", y cuales son las causas de las fluctuaciones coyunturales. 


\section{II}

¿Qué es la coyuntura, qué son las fluctuaciones coyunturales y cuáles son sus causas?

En principio, llamamos coyuntura la tendencia que acusa la evolución de la relación entre la demanda global y la ofer. ta global. Si la demanda global excede la oferta global, la. coyuntura se encuentra en fase ascendente, y tenemos un período de prosperidad. En la prosperidad, la producción y la ocupación crecen hasta alcanzar el límite constituido por la plena ocupación. Más allá de este límite, cualquier aumento de la demanda global conduce a la inflación, a menos que la oferta global pueda, por un correspondiente aumento de la productividad, seguir la demanda en su alza. En cambio, si la demanda global es inferior a la oferta global, la producción y la ocupación merman. Esta fase se llama depresión. La coyuntura ideal, desde el punto de vista económico y social, sería un crecimiento constante y parejo de la oferta global y de la demanda global.

Creemos útil hacer ahora una distinción de carácter limitativo: muchas de las opiniones y de los juicios que se expresan en las discusiones públicas, son afirmaciones de carácter global y objetivamente falsas, que se apoyan principalmente en la generalización o la exageración de verdades limitadas. Tales juicios se oyen con mayor trecuencia en las discusiones sobre las moditicaciones de precios. Se habla de una evolución de los precios en general, cuando en realidad, se trata del cambio de precios particulares, o de un movimiento de la estructura de los precios. De la misma manera, se habla con frecuencia de una evolución general de la coyuntura, por ejemplo de su "recalentamiento excesivo", cuando se trata solamente de una evolución particular de determinados sectores económicos. No hay una evolución de la coyuntura económica completamente general y pareja. El movimiento coyuntural no alcanza los diversos sectores de la economía en forma simultánea, ni con la misma intensidad. Esta realidad es de suma importancia para apreciar la evolución de las coyunturas, y para determinar el método a seguir en la política anticíclica. A pesar de la falta de uniformidad y de simultaneidad dentro de cada evolución coyuntural, podemos considerar la 
coyuntura como un fenómeno típico de la economía en su totalidad; no es el caso de ciertas fluctuaciones parciales, en las ventas o en la ocupación, que muchas veces se consideran, por error, como fenómenos de coyuntura: por ejemplo, las variaciones estacionales en ciertas ramas de la actividad económica (construcción, agricultura, turismo, etc.), o también las fluctuaciones en la producción o en la venta de ciertos artículos, causadas por una modificación de las necesidades o por el progreso de la técnica de producción.

\section{III}

Las fluctuaciones coyunturales son un fenómeno que puede producirse solamente en una economía de mercado, con un grado relativamente alto de industrialización y un sistema monetario y crediticio bien desarrollado.

Toda economía de mercado en la cual no se practique una política anticíclica activa, pasa necesariamente por variaciones coyunturales.

La forma y amplitud de estas fluctuaciones se han modificado en el curso de la historia, de acuerdo a la evolución de la economía de mercado y de la política económica.

En ciertas condiciones, una política coyuntural activa puede mitigar considerablemente las fluctuaciones cíclicas de la economía de mercado, por la aplicación de medidas que respetan el juego libre del mercado.

En la economía de mercado libre, las decisiones sobre las inversiones y sobre la distribución de los ingresos entre el consumo y el ahorro, están en manos de los empresarios y de los consumidores, quienes las toman independientemente, teniendo en cuenta solamente sus conveniencias particulares. Se deciden por las inversiones, el consumo o el chorro, según las condiciones momentáneas del mercado, y sobre las bases de sus previsiones relativas $a$ sus futuros ingresos y gastos. El período sobre el cual han de extenderse necesariamente los cálculos de rentabilidad probable de las inversiones proyectadas, es proporcional al grado de industrialización y de capitalización de la producción. A mayores variaciones en las necesidades o en la técnica de producción, mayores dificultades en la previsión de las perspectivas 
de ventas. Por depender de tantas condiciones la acertada previsión del porvenir, se llega muchas veces a decidir inversiones que, cuando se conozca la verdadera situación futura del mercado resultarán exageradas o insuficientes. Se podría pensar que, sobre el gran número de decisiones tomadas, estos errores se compensan. Pero la experiencia y la reflexión nos enseñan que, por la interdependencia de los mercados y el contagio psicológi$\mathrm{co}$, se difunden las expectativas optimistas o pesimistas. Es así como los errores en las decisiones de los empresarios (y también de los consumidores y de los ahorristas) resultan paralelos; se acumulan y provocan desequilibrios y fluctuaciones en la relación de la oferta total a la demanda total. Esta breve exposición no es, por supuesto, sino una explicación resumida e incompleta de las causas de los fenómenos coyunturales.

Llegamos a la conclusión de que la economía libre de mercado demuestra, por su misma estructura, una propensión a las variaciones cíclicas. En regímenes de economía dirigida o de dic. tadura económica, no existen fluctuaciones coyunturales; pero existen perturbaciones de otra naturaleza. En cierto sentido, se puede decir que las oscilaciones de la economía de mercado libre tienen algo de fatol. La incertidumbre del porvenir, y sus consecuencias, las decisiones equivocadas así como las variaciones cíclicas, aumentan considerablemente cuando la evolución económica está sujeta a perturbaciones causadas por influencias exteriores, principalmente por acontecimientos políticos 0 militares. Pero hay también perturbaciones profundas del equilibrio económico que no son de origen coyuntural, sino que dependen de fenómenos naturales. Esta afirmación vale especialmente para las regiones y las épocas de economía principalmente agraria. Los imprevisibles caprichos de la naturaleza, las condiciones meteorológicas, pueden tener por consecuencia variaciones considerables en el volumen de la cosecha, es decir, años de vacas gordas y años de vacas flacas. Sabia era la política del bíblico José cuando, en Egipto, quiso evitar, por una política nacional de compra y almacenamiento del grano, el peligro de hambre debido a los caprichos de la naturaleza. Pero José no era un economista de coyuntura, porque la política coyuntural no considera inal- 
terables las fluctuaciones de la producción, sino que busca a manera de atenuar aquellas fluctuaciones que son causadas por el hombre y no por la naturaleza.

\section{IV}

Examinando la histcria económica de los últimos 130 años, es decir desde el principio de la industrialización y del liberalismo económico, vemos que las formas, la amplitud y las causas de las fluctuaciones cíclicas, han cambiado mucho. Tanto para la ciencia económica como para la política coyuntural, es muy importante comprender bien estos cambios, so pena de querer aplicar a los problemas de hoy las soluciones de ayer. Hay tres iipos principales de evolución coyuntural, que caracterizan respectivamente el siglo XIX, el período comprendido entre las dos guerras mundiales, y la postguerra actual.

La evolución coyuntural del siglo XIX se caracteriza por el cumento continuo del producto social y del promedio del nivel de vida. Su tendencia ascendente varía en cuanto a su ritmo, es decir que pasa por estancamientos pasajeros, pero nunca por un período de contracción. Las fluctuaciones cíclicas del sigio XIX eran relativamente regulares, a tal punto que se pudo hablar de ciclos económicos de 7 a 12 años. Estas oscilaciones se debilitaron en los últimos años del siglo XIX y en los primeros del siglo XX. Los precios y los salarios eran relativamente flexibles, tanto hacia arriba como hacia abajo. La vida económica, en su conjunto, estaba caracterizada por una creciente libertad de movimiento de las mercancías, de los medios de pago y de las personas, especialmente en el orden internacional. Los gobiernos practicaban la doctrina de la no-intervención. Es muy notable que el desarrollo económico del siglo XIX, no haya sido perturbado por ninguna influencia extra-económica de importancia.

La evolución cíclica del período comprendido entre las dos guerras mundiales difiere mucho de aquélla del siglo XIX. Las crisis que trajo la primera parte de este período fueron crisis de readaptación y de inflación; fueron seguidas, especialmente en los Estados Unidos, de una prosperidad reforzada artificialmente por la especulación, y que duró hasta 1929. Esta fecha marca el 
principio de la crisis económica mundíal, con sus largos años de desocupación masiva, su contracción extraordinaria de la producción y del comercio mundial, y una caída sin precedente de los precios. Este fenómeno cíclico tenía causas principalmente Exógenas: se debía ante todo a los efectos de la guerra, a los tratados de paz y a las reparaciones. Después de la primera guerra mundial, el intervencionismo estatal fue creciendo, y después de la crisis económica mundial, la política económica se encaminó hacia el dirigismo; se trató de hacer una política coyuntural activa sobre una base puramente nacional, con tendencia autárquica. A partir del año 1934 aproximadamente, van desapareciendo las fluctuaciones cíclicas porque la política económica está guiada por la preocupación del rearme, y porque la economía de guerra lleva a un permariente exceso de la demanda.

Después de la segunda guerra mundial se volvió, en principio, a una economía de mercado. El fenómeno cíclico, por lo tanto, habría tenido que reaparecer. Pero hasta ahora, a parte de variaciones de poca importancia en el ritmo de la expansión de la economía, el desarrollo de la coyuntura ha sido relativamente favorable y constante. A diferencia del período de entreguerra, el desarrollo económico europeo desde 1945 no se enfrenta con problemas de deudas de guerra y de reparaciones, sino que encuentra el apoyo decidido de los Estados Unidos, y la tendencia de la política económica se caracteriza actualmente por la supresión progresiva de los controles y de los obstáculos al movimiento económico, es decir, por una liberalización creciente. Por mucho tiempo todavía, existe una gran necesidad de reconstrucción, y hay posibilidades inagotables de ampliar las necesidades. Las nuevas olas del progreso técnico restan validez a la teoría del estancamiento secular. Los precios y salarios se han vuelto muy reacios a la baja, pero han conservado su flexibilidad hacia arriba. Así es como el peligro principal para el desarrollo coyuntural en esta postguerra no es la depresión ni la deflación. sino la inflación. Una gran parte de la demanda y de la inversión total está en manos del Estado, y es relativamente más estable que la demanda y la inversión privadas. La especulación con valores ya no tiene mucha importancia y la autofinanciación ha crecido mucho, frente a la financiación con capitales ajenos. La 
política económica, tanto de los gobiernos como de los empresarios, toma la coyuntura mucho más en cuenta. Las experiencias de la política coyuntural y las nociones de la teoría cíclica han hecho grandes progresos. Todos estos factores contribuyen a reducir, mucho más que en el pasado, el peligro de una contracción depresiva y deflacionista y de una inflación desenfrenada.

¿Hasta qué punto y en qué condiciones una política coyuntural activa puede mitigar la tendencia de la economía libre de mercado a pasar por variaciones cíclicas, sin por eso renunciar al principio mismo de la economía de mercado?

En la opinión de muchos economistas, tanto teóricos como prácticos, del siglo XIX, las fluctuaciones cíclicas eran fenómenos secundarios inevitables, que acompañaban necesariamente la economía capitalista en su fogoso crecimiento. No pocos consideraban estas oscilaciones como un elemento netamente positivo, como un proceso de auto-purificación de la economía, por el cual resultaban eliminadas del proceso económico las empresas marginales, de bajo rendimiento, que ya no podían hacer frente a las exigencias impuestas por el ritmo del desarrollo económico.

Carlos Marx, y con él muchos de los socialistas que habían recibido su influencia, creían además en un proceso fatal, por el cual el desarrollo de la economía cxpitalista tenía no solamente una propensión a las fluctuaciones cíclicas, sino que provocaba crisis periódicas cada vez más graves, que tenían que desembocar en el derrumbe del capitalismo. La consecuencia sería la socialización de los medios de producción, y con ella la desaparición de las crisis. Hasta entre los llamados socialistas liberalizantes de nuestros tiempos, que profesan cierta simpatía a las ideas de economía de mercado y de libre competencia, conserva todo su vigor la opinión según la cual la nacionalización de las industrias claves representaría un medio sumamente eficaz para evitar las fluctuaciones cíclicas. Mucho más importante que la doctrina marxista sobre las crisis, es hoy la teoría según la cual las fluctuaciones coyunturales podrían ser prácticamente evitadas por 
una política de plena ocupación. Invocando - muchas veces sin razón- a Keynes, se ha formado un grupo de economistas que considera posible asegurar la plena ocupación en forma continua, mediante una política presupuestaria de déficit y de superavit, que se adapte constantemenie a la situación de la coyuntura. Estos economistas consideran que el equilibrio del presupuesto carece de importancia. Más primitiva, pero más común todavía, es la creencia en la posibilidad de eliminar toda tendencia a apartarse de la alta coyuntura y del pleno empleo, gracias a un aumento oportuno de los gastos públicos, ante todo en el terreno de las prestaciones sociales y de las obras públicas, y gracias a un aumento de los ingresos, o sea principalmente de los salarios. Hemos de reconocer que existen medios de política económica que permiten asegurar prácticamente el pleno empleo an forma total. ¿Pero a qué precio? No solamente la experiencia práctica, sino también los adelantos de la ciencia económica, nos demuestran que la política estricta de pleno empleo tiene inevitablemente consecuencias inflacionarias. En otras palabras: una política prolongada de plena ocupación total, se paga con la desvalorización de la moneda, y con la pérdida de las libertades económicas. El camino de la inflación y de la dictadura económica no lleva a ninguna solución verdadera de los problemas originados por los ciclos económicos; conduce solamente a una seudosolución ilusoria, cuyas consecuencias son peores, económica y socialmente, que las fluctuaciones limitadas de la coyuntura y de la tasa de ocupación.

¿Cuáles son, entonces, las condiciones necesarias para elaborar una política coyuntural exitosa y fundamentada en la economía de mercado?

El elaborador de la política económica debe tener una idea clara de la situación coyuntural y de la tendencia de su evolución. No hay duda que la investigación económica y la estadística coyuntural tienen ampliamente la posibilidad de proporcionar a los estadistas responsables de la política anticíclica los datos más importantes sobre la estructura y la evolución de los precios, de los salarios, del volumen del circulante y del crédito, del ahorro y de las inversiones, de la producción y de la productividad, de la balanza comercial y de la balanza de pagos. Hoy 
día estos datos se pueden conseguir poco tiempo después de los hechos que registran. Pero no es tan sencillo elaborar juicios con respecto a las relaciones que unen todos estos elementos; también en este aspecto se han hecho, sin embargo, grandes progresos en los últimos años, especialmente en ei cálculo de la renta nacional. Mucho más difícil es apreciar la tendencia del desarrollo cíclico. Si la política coyuntural quiere no solamente corregir, a posteriori, los daños ya ocurridos, sino también evitar los recesos, entonces el estadista responsable de los asuntos económicos debe tener la posibilidad de prever el porvenir por lo menos eil la medida en que tal previsión sea necesaria para la utilización eficaz de los instrumentos de política coyuntural. Así llegamos a la cuestión tan importante de la posibilidad de hacer pronósticos acertados en asuntos económicos y coyunturales. Friedrich Lutz, de Zurich, defiende la tesis (1) de la imposibilidad fundamental de prever con exactitud la evolución económica a largo plazo. Porque si, por ejemplo, se pudiese predecir con certeza que los precios de determinadas mercancías subirán en un $20 \%$ en el curso de los próximos seis meses, los compradores, basándose en esta previsión, comprarían mucho más de lo que sin ella hubiesen comprado; por lo tanto, los precios subirían mucho más de lo anunciado por esta misma predicción. Así llega a afirmar el Profesor Lutz: "Una previsión, correcta en principio, se vuelve necesariamente errónea una vez publicada, admitida y utilizada como base para los negocios". A pesar de tal opinión, creemos que existe la posibilidad, para la política anticíclica, de hacer previsiones a corto plazo y en forma condicional, apoyándose en análisis científicos, y particularmente estadísticos. El especialista en problemas coyunturales puede decir: si no se modifica sensiblemente el comportamiento actual de los consumidores, de los ahorristas y de los inversores, y si tanto los grupos de intereses como el gobierno mantienen en materia económica su política actual, entonces la coyuntura ha de evolucionar en el futuro próximo en tal o cual sentido. Las predicciones condicionales con un grado más o menos elevado de probabilidad son no solamente posibles, sino que constituyen la razón y el fin de la investigación económica.

(1) Friedrich A. LUTZ; Das Problem der Wirtschaftsprognosen, en Recht und Staat in Geschichte und Gegenwiant, No 185, Tubinga, 1955. 


\section{PROBLEMAS Y VICISITUDES DE LA POLITICA COYUNTURAL}

Cuanto más breve sea el tiempo que necesita un ministro de economía para tomar y ejecutar ciertas decisiones, tanto más fácil será proporcionarle los datos que necesita sobre la situación coyuntural y la tendencia de su evolución. Por este motivo, es muy importante establecer y utilizar métodos de política anticíclica que puedan aplicarse en relativamente poco tiempo. Igual importancia reviste la práctica de una política general económica y social que tenga por fundamento la invariabilidad de los objetivos y de los principios de organización político-económica, y que además asegure por un período largo la estabilidad de la moneda, dando así al consumidor y al ahorrista esta confianza en el futuro," que es la condición más importante para el desarrollo relativamente equilibrado de la economía.

\section{I}

Suponiendo que la situación política mundial se estabilice progresivamente, o por lo menos que no empeore, considero que dos fenómenos han de causar fluctuaciones cíclicas en un futuro próximo:

1) La inconstancia de la política económica: Los protagonistas de la economía se encuentran con demasiada frecuencia frente a nuevas situaciones y nuevas disposicicnes, debido a que ciertos grupos de intereses presentan continuamente nuevas exigercias, dejando sin descanso la máquina legislativa económica y la administración político-económica.

2) La falta de unidad en la política económica: A medida que la política económica se transforma en una política de compromiso entre las fuerzas en pugna, los instrumentos político-coyunturales disponibles, en vez de complementarse, irán estorbándose y paralizándose recíprocamente.

Otra condición para el éxito de una política de estabilización del ciclo, es la coordinación internacional de la política coyuntural. "Coyuntura" viene de "conjungere", es decir, unir. En una economía mundial dominada por la división del trabajo, las probabilidades de aumento del nivel de vida son proporcionales a la libertad de movimiento internacional de las mercancías, de los 


\section{ESTUDIOS ECONOMICOS}

medios de pago y de las personas. Pero al ser más libre este movimiento y más intrincada la maraña de las relaciones económicas mundiales, se vuelve más rígida la interdependencia coyuntural de las economías nacionales. Resulta evidente que una política coyuntural eficiente es tanto más fácil de practicar cuanto menor es el volumen del comercio exterior con relación al producto social. Por ejemplo, la evolución cíclica de los Estados Unidos depende mucho menos de la situación del mercado mundial, que la evolución cíclica de Suiza o de Austria. Es precisamente para las economías nacionales de poco volumen, pero intimamente ligadas al mercado mundial, que las variaciones de la coyuntura internacional tienen una importancia absolutamente decisiva. Pero nada hay tan perjudicial para la política de estabilización coyuntural, como el intento de practicar una política anticíclica nacional, en forma autónoma, tratando de protegerse de las fluctuaciones coyunturales de la economía mundial mediante el control del comercio exterior. Así es cómo, por motivos de política anticíclica, los pequeños países deben tener el máximo interés en que las relaciones económicas internacionales se apoyen en los principios de la economía de mercado.

\section{I I}

En un proceso de estabilización de la coyuntura, la condición más importante para el éxito es la estabilidad del valor de la moneda. Una coyuntura excesivamente ascendente conduce $a$ la inflación, y una coyuntura que cae en la depresión está ligada a la deflación. Nada hay más engañador que la experiencia de los dos últimos decenios, en los cuales el exceso inflacionista de la demanda sobre la oferta existe simultáneamente con la penuria de mano de obra en vez de la escasez de trabajo. Esta situación ha hecho creer a algunos que un aumento, lento pero continuo, del nivel general de los precios, garantizaría la permanencia de una coyuntura alta y de la plena ocupación, y aseguraría a los asalariados una posición fuerte en el mercado del trabajo. Los que profesan tal opinión no se dan cuenta, o no aprecian suficientemente, que este lento proceso inflacionario conduce, tarde o temprano, a la ruptura de los principios de la economía de 
mercado, y desemboca forzosamente en una fuerte reglamentación de los precios y de los abastecimientos, por no mencionar otras consecuencias más graves.

Todo indica que el peligro de deflación, tan característico de la entreguerra, no existe más hoy, ni se volverá a presentar en el futuro previsible. La política sindical ha vuelto los salarios inmovibles hacia abajo; también los precios de las mercancías en su promedio han llegado a ser reacios a la baja. La competencia entre los precios ha sido sustituida en gran parte por la competencia entre las calidades, o limitada por un sistema de convenios y acuerdos. Los gobiernos son mucho más accesibles que en épocas anteriores, a los pedidos de fijación de precios mínimos. La parte importante que corresponde al Estado en la demanda total, actúa fuertemente en contra de cualquier tendencia deflacionista; porque el crecimiento de los gastos públicos parece ser ya un proceso irreversible. El peligro monetario decisivo de nuestra época es la inflación secular lenta y encubierta. Si queremos asegurar una organización económica liberal, eficiente y socialmente justa, la primera condición es la estabilización del valor de la moneda, sin ninguna concesión a una pretendida política coyuntural levemente inflacionista.

En relación con lo que acabamos de mencionar, creemos necesario llamar la atención sobre un error todavía más común entre los políticos y los hombres de ciencia, error que consiste en pensar que las causas principales de las variaciones cíclicas son la insuficiencia o el exceso del volumen adscripto al dinero y al crédito por la política monetaria y crediticia. Tal concepción lleva naturalmente a la conclusión de que los instrumentos principales de una política anticíclica eficiente deben ser la expansión y ia contracción de los volúmenes del dinero y del crédito. En otras palabras: las políticas de descuento, de mercado abierto, de reservas y de liquidez, son presentadas como los instrumentos más eficaces para acelerar o frenar la evolución cíclica. Esta concepción de la política coyuntural monetaria y crediticia, estrechamente relacionada con la "teoría cuantitativa del dinero" que ha trastornado ya tantas cabezas, no representa siquiera una parte de la verdad-que en tal caso se podría completar- sino que es fundamentalmente dudosa. 
Las causas de las fluctuaciones cíclicas no se encuentran en la acción del banco de emisión o de los bancos de crédito, sino ante todo en la variación de la demanda total, en parte por el aumento de los gastos públicos, por el aumento de los ingresos ( [los salarios!) y del consumo, y también por el aumento de los gastos de inversión, particularmente cuando exceden en volumen la oferta total.

El aumento de la cantidad de dinero y de crédito es la consecuencia, no la causa, del aumento de la demanda. Esta consecuencia puede evitarse si el banco de emisión y los bancos de crédito son suficientemente independientes del gobierno, y si no están dispuestos a satisfacer la demanda creciente, tanto pública como privada, de medios de pago. Pero si el parlamento apoya el aumento de los gastos públicos, y si los empresarios y consumidores quieren aumentar sus inversiones y sus gastos de consumo, entonces el banco de emisión y los bancos de crédito pueden difícilmente mantener una posición firme, y rehusarse a extender estos medios de pago y estos créditos. Una política coyuntural activa no consiste primariamente en disposiciones de política monetaria y crediticia, sino en medidas destinadas a restringir los gastos públicos y privados de inversión y de consumo. La obligación del banco de emisión y de los bancos de crédito consiste en ir adaptando los volúmenes de dinero y de crédito a las fluctuaciones en la demanda de dinero y de crédito. Las medidas de expansión y de contracción de la política monetaria y crediticia son, por lo tanto, principalmente una reacción ante las variaciones cíclicas y contra las medidas de política coyuntural; por otra parte, constituyen también la condición para el éxito de una política anticíclica activa, pero no la causa ni el instrumento principal de esta política. Así llegamos a la siguiente conclusión: que no son actualmente el banco de emisión ni los bancos de crédito los que llevan la responsabilidad principal en la política coyuntural, sino las personas y entidades que tienen a su cargo la elaboración del presupuesto nacional y la estructuración de los salarios, sin olvidar el papel importante de aquéllos que tienen la misión de asegurar, en lo posible, la formación de los precios según el principio de la libre competencia. 
Siempre que el desarrollo económico y la confianza no estén sometidos a perturbaciones originadas por la política internacional o por los problemas de la defensa nacional, existe hoy la plena posibilidad de atenuar en tal grado las fluctuaciones cíclicas, que se las puede considerar como un inconveniente soportable del sistema de la economía de mercado. Para obtener este resultado, basta recurrir a los instrumentos llamados "conformes al libre mercado" en el marco de las políticas presupuestaria, de salarios, monetaria y de comercio exterior. Cuanto mayor sea - a largo plazo - el aumento del nivel de vida, más fácil será proteger, con medidas sociales específicas, los sectores de población perjudicados por las inevitables fluctuaciones cíclicas remanentes.

Bien comprendida, la política coyuntural, en el sentido de aquella política que persigue la mayor suavización posible de las oscilaciones cíclicas, es una tarea de crección y estructuración que requiere no solamente de parte del estado una política coyuntural inteligente, capaz y consecuente, sino también, de parte de las entidades y organizaciones interesadas, un comportamiento responsable, y consciente de la coyuntura, ya que estas agrupaciones se han hecho cada vez más partícipes de la estructuración y de la conducción de la política económica y social.

Quisiera resumir mis reflexiones con las palabras de optimismo realista del Prof. Arthur Burns, director del Consejo de asesores económicos de los Estados Unidos ( ${ }^{*}$ ), en su informe de 1954: "La experiencia nos ha enseñado que los gobiernos pueden hacer mucho para dominar las fluctuaciones cíclicas. Pero no tenemos motivos para suponer que pueden impedirlas totalmente". A estas palabras, quisiera sin embargo agregar lo siguiente: No son solamente los gobiernos los que pueden hacer mucho, sino ante todo los protagonistas del mercado del trabajo, los organismos que representon los diversos grupos de intereses económicos, así como cada uno de los empresarios, cada uno de los consumidores, y cada uno de los ahorristas.

(*) Council of Economic Advisers. (N. T.). 


\section{ESTUDIOS ECONOMICOS}

Actualmente, dominar las tareas de la política coyuntural no es tanto cuestión de conocimiento de la teoría cíclica y de dominio del instrumental de la política coyuntural, como un problema de creación y formación de una voluntad unificada en materia de política económica y coyuntural. Aquí termina el arte del economista y del técnico especializado, y empieza la tarea política, difícil por cierto, de evitar compromisos dudosos en la política coyuntural, y hacer prevalecer una concepción unitaria y consecuente en materia de política anticíclica. También en este terreno, la moderna democracia de masas y de agrupaciones tiene todavía que hacer la prueba de su eficiencia. Porque nada puede hacer peligrar tanto la tarex de atenuar las variaciones cíclicas mediante disposiciones de política económica, como las contradicciones fundamentales entre las opiniones y exigencias político-coyunturales de aquellas organizaciones y de aquellos funcionarios cuya actuación combinada determina la orientación de la política económica - y especialmente de la política coyyuntural- de una nación.

Universidad de Viena

Theodor Pütz

(Manuscrito en alemán. Versión española de Pablo J. Gallez). 